\title{
Prevalência de raiva animal no estado do Pará, no período de 2004 a 2013
}

\section{Prevalence of animal rabies in Pará State, Brazil, from 2004 to 2013}

Érika Dayane Leal Rodrigues' ${ }^{1}$ Taiana Andrade Freitas², Francisco Amilton dos Santos Paiva ${ }^{2}$, Armando de Souza Pereira ${ }^{2}$, Taciana Fernandes Souza Barbosa Coelho², Elizabeth Salbé Travassos da Rosa², Alexandre do Rosário Casseb², Livia Medeiros Neves Casseb²

' Universidade Federal Rural da Amazônia, Instituto da Saúde e Produção Animal, Belém, Pará, Brasil

2 Instituto Evandro Chagas/SVS/MS, Seção de Arbovirologia e Febres Hemorrágicas, Ananindeua, Pará, Brasil

\section{RESUMO}

OBJETIVO: Descrever a prevalência da raiva animal no estado do Pará, no período de 2004 a 2013. MATERIAIS E MÉTODOS: Foi realizado um levantamento no banco de dados dos encéfalos recebidos no Laboratório de Diagnóstico de Raiva da Seção de Arbovirologia e Febres Hemorrágicas do Instituto Evandro Chagas, de 2004 a 2013 , oriundos das seis mesorregiões do Pará. RESULTADOS: Das 13.987 amostras recebidas e analisadas no Laboratório, 1,26\% (176/13.987) foram positivas. Os registros positivos, por espécies examinadas, foram: 34,78\% de equinos (8/23); $34,71 \%$ de bovinos $(42 / 121) ; 25,00 \%$ de suínos $(3 / 12) ; 1,33 \%$ de felinos $(5 / 375) ; 1,22 \%$ de caninos (105/8.633); 0,27\% de quirópteros (13/4.797); e as demais espécies (caprinos, ovinos, símios, leporídeos, procionídeos, roedores e não identificadas) foram negativas (0/26). A Mesorregião Sudoeste Paraense foi a que apresentou o maior índice de positividade (6,15\%). CONCLUSÃO: Os resultados apresentados neste estudo ressaltam a importância da imunização anual de animais de produção, bem como enfatizam a relevância das campanhas de vacinação de animais domésticos para o controle da raiva urbana, a fim de reduzir a incidência e a letalidade da doença.

Palavras-chave: Vírus da Raiva; Diagnóstico; Vigilância Epidemiológica.

\begin{abstract}
OBJECTIVE: To describe the prevalence of animal rabies in Pará State, Brazil, from 2004 to 2013. MATERIALS AND METHODS: A survey was performed using database of brains received at Rabies Diagnosis Laboratory of Arbovirology and Hemorrhagic Fever Section of Instituto Evandro Chagas, from 2004 to 2013, came from the six Medium Regions of Pará. RESULTS: Of the 13,987 samples received and analyzed in laboratory, 1.26\% $(176 / 13,987)$ were positive. The positive records, by species examined, were: $34.78 \%$ of horses $(8 / 23) ; 34.71 \%$ of cattle $(42 / 121) ; 25.00 \%$ of pigs $(3 / 12) ; 1.33 \%$ of felines $(5 / 375) ; 1.22 \%$ of canines $(105 / 8,633) ; 0.27 \%$ of chiropters $(13 / 4,797)$; and the other species (goats, sheep, simians, leporids, procyonids, rodents, and unidentified) were negative (0/26). Mesorregião Sudoeste Paraense presented the highest positivity rate (6.15\%). CONCLUSION: The results presented in this study emphasize the importance of the annual immunization of production animals, as well the vaccination campaigns of domestic animals for the control of urban rabies, in order to reduce the incidence and lethality of the disease.
\end{abstract}

Keywords: Rabies Virus; Diagnosis; Epidemiological Surveillance. 


\section{INTRODUÇÃO}

A raiva é uma doença infecciosa aguda, causada pelo Rabies lyssavirus (vírus da raiva - RABV - "rabies virus"), que acomete o sistema nervoso central e se caracteriza por provocar um quadro de encefalite ${ }^{1,2}$. É uma doença zoonótica, transmitida geralmente por mordeduras e arranhaduras $3,4,5$

Embora a raiva seja uma enfermidade imunoprevenível, a preocupação ainda persiste, em virtude de sua progressão fatal e do expressivo número anual de vítimas humanas, motivos suficientes para ser considerada um sério problema de saúde pública, além dos grandes prejuízos causados à pecuária ${ }^{6}$. Sua manutenção e perpetuação ocorrem por diversos animais; os principais envolvidos são os carnívoros silvestres e domésticos e os morcegos hematófagos e não hematófagos. Nos países em desenvolvimento, o foco de atuação das entidades competentes contra a doença está relacionado à sua disseminação por carnívoros domésticos, sobretudo os cães, que facilitam a manutenção da cadeia de transmissão animal doméstico/homem em áreas urbanas ${ }^{7}$.

Desde a antiguidade, a raiva afeta o ser humano; em 2015, cerca de 59.000 mortes por raiva humana foram registradas no mundo, particularmente na Ásia e na África, continentes onde a doença é endêmica ${ }^{8}$. É considerada uma doença negligenciada, pois recebe poucos investimentos em pesquisas, terapias e controle?

$\bigcirc$ ciclo epidemiológico da raiva é dividido em quatro (urbano, rural, silvestre aéreo e silvestre terrestre) que se inter-relacionam, possibilitando que haja uma interação entre as espécies de animais responsáveis pela manutenção do ciclo de transmissão ${ }^{10,11}$.

A partir dos anos 1980, os cães foram considerados os principais reservatórios do RABV; todavia, as campanhas massivas de vacinação culminaram na redução do número de casos nessa espécie. A partir de 2004, o morcego hematófago Desmodus rotundus tornou-se o principal responsável pela manutenção da raiva, sobretudo, nos ciclos silvestre aéreo e rural, sendo comum a presença dessa espécie em regiões com rebanhos de gado. A doença em herbívoros gera custo alto, devido às medidas de controle e prevenção serem caras, além dos prejuízos causados na produção ${ }^{12,13}$.

$\mathrm{Na}$ América do Sul, essa mudança no ciclo epidemiológico da raiva começou a chamar atenção quando ocorreu um surto de raiva humana, causada por Desmodus rotundus, na Amazônia Legal Brasileira, mais especificamente nos estados do Pará e do Maranhão, em 2004 e $2005^{12}$.

Acerca do diagnóstico da raiva, a Organização Mundial da Saúde (OMS) recomenda o uso das técnicas de imunofluorescência direta ${ }^{14} \mathrm{e}$ isolamento viral em camundongo ${ }^{15,16}$ como os principais métodos para 0 diagnóstico específico da doença. São testes altamente sensíveis e específicos e utilizados simultaneamente para a detecção de antígenos virais e tentativa de isolamento viral ${ }^{17}$.

objetivo deste estudo foi realizar um levantamento dos casos de raiva animal procedentes do estado do Pará, identificados a partir dos dados de amostras enviadas para diagnóstico, de 2004 a 2013, ao Laboratório de Diagnóstico de Raiva do Instituto Evandro Chagas (IEC), órgão vinculado à Secretaria de Vigilância em Saúde do Ministério da Saúde.

\section{MATERIAIS E MÉTODOS}

Trata-se de um estudo descritivo, utilizando dados retrospectivos oriundos de banco de dados, para a obtenção de informações sobre os encéfalos examinados e os resultados obtidos no Laboratório de Diagnóstico de Raiva da Seção de Arbovirologia e Febres Hemorrágicas (SAARB) do IEC, no período de 2004 a 2013, tendo como área de abrangência as seis mesorregiões do estado do Pará.

Os dados obtidos foram inseridos em uma planilha do programa Microsoft Excel 2007, que resultou na construção de tabelas e análises estatísticas. As amostras foram separadas de acordo com espécie, ano e mesorregião.

\section{RESULTADOS}

Foram examinadas 13.987 amostras quanto à presença de infecção pelo RABV, divididas em: 8.633 caninos, 4.797 quirópteros, 375 felinos, 121 bovinos, 23 equinos, 12 suínos, sete roedores, quatro símios, dois caprinos, dois leporídeos, um ovino, um procionídeo (quati) e nove amostras sem identificação do animal. $\bigcirc$ maior percentual de positividade foi encontrado nos equinos $(34,78 \%$; 8/23), seguido dos bovinos $(34,71 \%$; 42/121) (Tabela 1).

Dentre as mesorregiões, 981 amostras eram provenientes do Baixo Amazonas, 179 do Sudoeste Paraense, 1.094 do Marajó, 4.730 do Sudeste Paraense, 2.630 do Nordeste Paraense, 4.364 da Região Metropolitana de Belém e nove de localização desconhecida. A Mesorregião Sudoeste Paraense foi a que apresentou o maior índice de positividade, 6,15\% (11/179) no período pesquisado (Tabela 2).

\section{DISCUSSÃO}

A epidemiologia da raiva varia de acordo com a área geográfica. Em áreas endêmicas, o RABV é mantido em um ciclo urbano, tendo como reservatórios cães e gatos, e/ou em um ciclo selvagem, no qual os reservatórios variam dependendo da região ${ }^{10,18,19}$.

Entre 2004 e 2013, foram confirmados 690 casos de raiva canina no Brasil19,20. Neste estudo, apesar do grande número de amostras de caninos, levando-se em consideração os 10 anos analisados, o valor de prevalência da raiva nessa espécie foi de 1,22\% (105/8.633), sendo mais prevalente nos anos de 2006 e 2007 , com 1,73\% (27/1.558) e 2,85\% (35/1.226) casos positivos, respectivamente. Apenas nos anos de 2005 e 2012, o número de casos de raiva bovina superou os casos de raiva canina. A circulação do RABV está sob controle na população canina em grande parte da América Latina; porém, ações de vigilância devem ser reforçadas e suportes de recursos políticos, técnicos e em educação devem ser continuados. Se a vigilância for reduzida, o vírus pode se reestabelecer no ciclo urbano ${ }^{20}$. 
Tabela 1 - Amostras positivas/examinadas e percentual de positividade para raiva animal, por espécie, diagnosticadas no IEC, de 2004 a 2013

\begin{tabular}{|c|c|c|c|c|c|c|c|c|c|c|c|}
\hline \multirow{2}{*}{ Espécies } & \multicolumn{11}{|c|}{ Amostras positivas/examinadas (\%) } \\
\hline & 2004 & 2005 & 2006 & 2007 & 2008 & 2009 & 2010 & 2011 & 2012 & 2013 & Total \\
\hline Bovinos & $\begin{array}{c}3 / 12 \\
(25,00 \%)\end{array}$ & $\begin{array}{c}22 / 38 \\
(57,89 \%)\end{array}$ & $\begin{array}{c}11 / 30 \\
(36,67 \%)\end{array}$ & $\begin{array}{c}1 / 5 \\
(20,00 \%)\end{array}$ & $\begin{array}{c}4 / 13 \\
(30,77 \%)\end{array}$ & $\begin{array}{c}-/ 4 \\
(-)\end{array}$ & $\begin{array}{l}-16 \\
(-)\end{array}$ & $\begin{array}{c}-/ 10 \\
(-)\end{array}$ & $\begin{array}{c}1 / 3 \\
(33,33 \%)\end{array}$ & $\begin{array}{l}-/- \\
(-)\end{array}$ & $\begin{array}{c}42 / 121 \\
(34,71 \%)\end{array}$ \\
\hline Caninos & $\begin{array}{c}9 / 672 \\
(1,34 \%)\end{array}$ & $\begin{array}{l}9 / 1.418 \\
(0,63 \%)\end{array}$ & $\begin{array}{c}27 / 1.558 \\
(1,73 \%)\end{array}$ & $\begin{array}{c}35 / 1.226 \\
(2,85 \%)\end{array}$ & $\begin{array}{l}10 / 967 \\
(1,03 \%)\end{array}$ & $\begin{array}{c}7 / 676 \\
(1,04 \%)\end{array}$ & $\begin{array}{c}1 / 594 \\
(0,17 \%)\end{array}$ & $\begin{array}{c}7 / 704 \\
(0,99 \%)\end{array}$ & $\begin{array}{c}-/ 398 \\
(-)\end{array}$ & $\begin{array}{c}-/ 420 \\
(-)\end{array}$ & $\begin{array}{c}105 / 8.633 \\
(1,22 \%)\end{array}$ \\
\hline Quirópteros & $\begin{array}{c}1 / 791 \\
(0,13 \%)\end{array}$ & $\begin{array}{l}4 / 816 \\
(0,49 \%)\end{array}$ & $\begin{array}{l}4 / 670 \\
(0,60 \%)\end{array}$ & $\begin{array}{c}2 / 453 \\
(0,44 \%)\end{array}$ & $\begin{array}{c}-/ 317 \\
(-)\end{array}$ & $\begin{array}{c}-/ 220 \\
(-)\end{array}$ & $\begin{array}{c}-/ 301 \\
(-)\end{array}$ & $\begin{array}{c}1 / 548 \\
(0,18 \%)\end{array}$ & $\begin{array}{l}1 / 455 \\
(0,22 \%)\end{array}$ & $\begin{array}{c}-/ 226 \\
(-)\end{array}$ & $\begin{array}{c}13 / 4.797 \\
(0,27 \%)\end{array}$ \\
\hline Felinos & $\begin{array}{c}2 / 51 \\
(3,92 \%)\end{array}$ & $\begin{array}{c}2 / 70 \\
(2,86 \%)\end{array}$ & $\begin{array}{c}-/ 57 \\
(-)\end{array}$ & $\begin{array}{c}-/ 35 \\
(-)\end{array}$ & $\begin{array}{c}-/ 22 \\
(-)\end{array}$ & $\begin{array}{c}-/ 35 \\
(-)\end{array}$ & $\begin{array}{c}-/ 25 \\
(-)\end{array}$ & $\begin{array}{c}1 / 37 \\
(2,70 \%)\end{array}$ & $\begin{array}{c}-/ 15 \\
(-)\end{array}$ & $\begin{array}{c}-/ 28 \\
(-)\end{array}$ & $\begin{array}{c}5 / 375 \\
(1,33 \%)\end{array}$ \\
\hline Equinos & $\begin{array}{c}1 / 4 \\
(25,00 \%)\end{array}$ & $\begin{array}{c}3 / 5 \\
(60,00 \%)\end{array}$ & $\begin{array}{c}1 / 1 \\
(100,00 \%)\end{array}$ & $\begin{array}{l}-/ 3 \\
(-)\end{array}$ & $\begin{array}{r}-/ 1 \\
(-)\end{array}$ & $\begin{array}{r}-/ 1 \\
(-)\end{array}$ & $\begin{array}{c}2 / 4 \\
(50,00 \%)\end{array}$ & $\begin{array}{l}-/ 3 \\
(-)\end{array}$ & $\begin{array}{c}1 / 1 \\
(100,00 \%)\end{array}$ & $\begin{array}{l}-/- \\
(-)\end{array}$ & $\begin{array}{c}8 / 23 \\
(34,78 \%)\end{array}$ \\
\hline Caprinos & $\begin{array}{l}-/- \\
(-)\end{array}$ & $\begin{array}{r}-/ 1 \\
(-)\end{array}$ & $\begin{array}{l}-1- \\
(-)\end{array}$ & $\begin{array}{l}-/ 1 \\
(-)\end{array}$ & $\begin{array}{l}-/- \\
(-)\end{array}$ & $\begin{array}{l}-/- \\
(-)\end{array}$ & $\begin{array}{l}-/- \\
(-)\end{array}$ & $\begin{array}{l}-1- \\
(-)\end{array}$ & $\begin{array}{l}-1- \\
(-)\end{array}$ & $\begin{array}{l}-1- \\
(-)\end{array}$ & $\begin{array}{c}-/ 2 \\
(-)\end{array}$ \\
\hline Ovinos & $\begin{array}{l}-/- \\
(-)\end{array}$ & $\begin{array}{l}-/- \\
(-)\end{array}$ & $\begin{array}{l}-/- \\
(-)\end{array}$ & $\begin{array}{l}-/- \\
(-)\end{array}$ & $\begin{array}{l}-/- \\
(-)\end{array}$ & $\begin{array}{r}-/ 1 \\
(-)\end{array}$ & $\begin{array}{l}-/- \\
(-)\end{array}$ & $\begin{array}{l}-1- \\
(-)\end{array}$ & $\begin{array}{l}-1- \\
(-)\end{array}$ & $\begin{array}{l}-1- \\
(-)\end{array}$ & $\begin{array}{r}-/ 1 \\
(-)\end{array}$ \\
\hline Suínos & $\begin{array}{l}-/- \\
(-)\end{array}$ & $\begin{array}{c}3 / 3 \\
(100,00 \%)\end{array}$ & $\begin{array}{c}-/ 2 \\
(-)\end{array}$ & $\begin{array}{l}-/- \\
(-)\end{array}$ & $\begin{array}{l}-/ 1 \\
(-)\end{array}$ & $\begin{array}{l}-/- \\
(-)\end{array}$ & $\begin{array}{l}-/- \\
(-)\end{array}$ & $\begin{array}{l}-/- \\
(-)\end{array}$ & $\begin{array}{l}-/ 5 \\
(-)\end{array}$ & $\begin{array}{l}-/ 1 \\
(-)\end{array}$ & $\begin{array}{c}3 / 12 \\
(25,00 \%)\end{array}$ \\
\hline Símios & $\begin{array}{l}-/- \\
(-)\end{array}$ & $\begin{array}{r}-/ 1 \\
(-)\end{array}$ & $\begin{array}{l}-/- \\
(-)\end{array}$ & $\begin{array}{c}-/- \\
(-)\end{array}$ & $\begin{array}{c}-/ 2 \\
(-)\end{array}$ & $\begin{array}{l}-/- \\
(-)\end{array}$ & $\begin{array}{r}-/ 1 \\
(-)\end{array}$ & $\begin{array}{l}-1- \\
(-)\end{array}$ & $\begin{array}{l}-1- \\
(-)\end{array}$ & $\begin{array}{l}-1- \\
(-)\end{array}$ & $\begin{array}{c}-/ 4 \\
(-)\end{array}$ \\
\hline Leporídeos & $\begin{array}{r}-/ 1 \\
(-)\end{array}$ & $\begin{array}{l}-/- \\
(-)\end{array}$ & $\begin{array}{l}-1- \\
(-)\end{array}$ & $\begin{array}{l}-/- \\
(-)\end{array}$ & $\begin{array}{l}-/ 1 \\
(-)\end{array}$ & $\begin{array}{l}-/- \\
(-)\end{array}$ & $\begin{array}{c}-/- \\
(-)\end{array}$ & $\begin{array}{c}-/- \\
(-)\end{array}$ & $\begin{array}{c}-/- \\
(-)\end{array}$ & $\begin{array}{c}-/- \\
(-)\end{array}$ & $\begin{array}{c}-/ 2 \\
(-)\end{array}$ \\
\hline Procionídeos & $\begin{array}{l}-/- \\
(-)\end{array}$ & $\begin{array}{l}-/- \\
(-)\end{array}$ & $\begin{array}{l}-/- \\
(-)\end{array}$ & $\begin{array}{l}-/ 1 \\
(-)\end{array}$ & $\begin{array}{l}-/- \\
(-)\end{array}$ & $\begin{array}{l}-/- \\
(-)\end{array}$ & $\begin{array}{l}-/- \\
(-)\end{array}$ & $\begin{array}{l}-/- \\
(-)\end{array}$ & $\begin{array}{l}-/- \\
(-)\end{array}$ & $\begin{array}{l}-1- \\
(-)\end{array}$ & $\begin{array}{l}-/ 1 \\
(-)\end{array}$ \\
\hline Roedores & $\begin{array}{l}-/- \\
(-)\end{array}$ & $\begin{array}{r}-/ 5 \\
(-)\end{array}$ & $\begin{array}{l}-/- \\
(-)\end{array}$ & $\begin{array}{r}-/ 1 \\
(-)\end{array}$ & $\begin{array}{l}-/- \\
(-)\end{array}$ & $\begin{array}{l}-/- \\
(-)\end{array}$ & $\begin{array}{l}-/- \\
(-)\end{array}$ & $\begin{array}{l}-/- \\
(-)\end{array}$ & $\begin{array}{r}-/ 1 \\
(-)\end{array}$ & $\begin{array}{l}-/- \\
(-)\end{array}$ & $\begin{array}{r}-/ 7 \\
(-)\end{array}$ \\
\hline $\begin{array}{l}\text { Não } \\
\text { identificadas }\end{array}$ & $\begin{array}{l}-/- \\
(-)\end{array}$ & $\begin{array}{c}-/ 2 \\
(-)\end{array}$ & $\begin{array}{c}-16 \\
(-)\end{array}$ & $\begin{array}{r}-/ 1 \\
(-)\end{array}$ & $\begin{array}{l}-/- \\
(-)\end{array}$ & $\begin{array}{l}-/- \\
(-)\end{array}$ & $\begin{array}{l}-/- \\
(-)\end{array}$ & $\begin{array}{l}-/- \\
(-)\end{array}$ & $\begin{array}{l}-1- \\
(-)\end{array}$ & $\begin{array}{l}-/- \\
(-)\end{array}$ & $\begin{array}{r}-/ 9 \\
(-)\end{array}$ \\
\hline Total & $\begin{array}{c}16 / 1.531 \\
(1,05)\end{array}$ & $\begin{array}{c}43 / 2.359 \\
(1,82 \%)\end{array}$ & $\begin{array}{c}43 / 2.324 \\
(1,85 \%)\end{array}$ & $\begin{array}{c}38 / 1.726 \\
(2,20 \%)\end{array}$ & $\begin{array}{c}14 / 1.324 \\
(1,06 \%)\end{array}$ & $\begin{array}{l}7 / 937 \\
(0,75 \%)\end{array}$ & $\begin{array}{c}3 / 931 \\
(0,32 \%)\end{array}$ & $\begin{array}{l}9 / 1.302 \\
(0,69 \%)\end{array}$ & $\begin{array}{c}3 / 878 \\
(0,34 \%)\end{array}$ & $\begin{array}{c}-1675 \\
(-)\end{array}$ & $\begin{array}{c}176 / 13.987 \\
(1,26 \%)\end{array}$ \\
\hline
\end{tabular}

Sinal convencional utilizado: - Dado numérico igual a zero, não resultante de arredondamento.

No período de 2004 a 2012, foram registrados 16.152 casos de raiva em herbívoros e suínos no Brasil, demonstrando alta prevalência nesta espécie ${ }^{21}$. Esses dados diferem dos obtidos neste estudo, onde a prevalência da doença nessas espécies foi baixa (53 casos positivos), sendo 42 bovinos, oito equinos e três suínos no mesmo período.

Os dados obtidos neste levantamento de 10 anos demonstraram a prevalência de casos de raiva em herbívoros, no Pará, especificamente em equinos e bovinos, de $34,78 \%(8 / 23)$ e $34,71 \%$ (42/121), respectivamente. Os períodos de diminuição ou de expansão dos casos de raiva nessas espécies podem ser atribuídos às medidas de controle aplicadas e às modificações antrópicas em áreas nunca antes adentradas, o que facilita a coexistência de condições epidemiológicas diversas, principalmente as relacionadas aos quirópteros. Embora essa prevalência seja alta, os casos positivos nesses animais vêm decrescendo no país como um todo, fato que pode estar relacionado ao aumento da utilização de vacinas antirrábicas. Porém, ainda se observa a ausência de envio de material para os laboratórios de referência por parte sobretudo dos veterinários, visto que muitos consideram apenas o diagnóstico clínico da doença, baseando-se somente na existência de resultados positivos de anos anteriores, bem como a comprovação da presença de morcegos hematófagos na região, levando-os a dispensar o diagnóstico laboratorial ${ }^{22,23}$. 
Tabela 2 - Amostras positivas/examinadas e percentual de positividade para raiva animal, por mesorregião do estado do Pará, diagnosticadas no IEC, de 2004 a 2013

\begin{tabular}{|c|c|c|c|c|c|c|c|c|c|c|c|}
\hline \multirow{2}{*}{ Mesorregiões } & \multicolumn{11}{|c|}{$\begin{array}{l}\text { Amostras positivas/examinadas } \\
(\%)\end{array}$} \\
\hline & 2004 & 2005 & 2006 & 2007 & 2008 & 2009 & 2010 & 2011 & 2012 & 2013 & Total \\
\hline Baixo Amazonas & $\begin{array}{c}-/ 143 \\
(-)\end{array}$ & $\begin{array}{c}-/ 230 \\
(-)\end{array}$ & $\begin{array}{c}-/ 167 \\
(-)\end{array}$ & $\begin{array}{l}1 / 109 \\
(0,92 \%)\end{array}$ & $\begin{array}{c}1 / 84 \\
(1,19 \%)\end{array}$ & $\begin{array}{c}-167 \\
(-)\end{array}$ & $\begin{array}{c}-165 \\
(-)\end{array}$ & $\begin{array}{c}-/ 54 \\
(-)\end{array}$ & $\begin{array}{c}-/ 32 \\
(-)\end{array}$ & $\begin{array}{c}-/ 30 \\
(-)\end{array}$ & $\begin{array}{l}2 / 981 \\
(0,20 \%)\end{array}$ \\
\hline $\begin{array}{l}\text { Sudoeste } \\
\text { Paraense }\end{array}$ & $\begin{array}{c}-/ 2 \\
(-)\end{array}$ & $\begin{array}{c}-/ 48 \\
(-)\end{array}$ & $\begin{array}{c}8 / 43 \\
(18,60 \%)\end{array}$ & $\begin{array}{c}1 / 24 \\
(4,17 \%)\end{array}$ & $\begin{array}{c}-/ 28 \\
(-)\end{array}$ & $\begin{array}{c}-/ 13 \\
(-)\end{array}$ & $\begin{array}{c}2 / 9 \\
(22,22 \%)\end{array}$ & $\begin{array}{c}-/ 8 \\
(-)\end{array}$ & $\begin{array}{l}-/- \\
(-)\end{array}$ & $\begin{array}{c}-/ 4 \\
(-)\end{array}$ & $\begin{array}{l}11 / 179 \\
(6,15 \%)\end{array}$ \\
\hline Maraió & $\begin{array}{l}3 / 426 \\
(0,70 \%)\end{array}$ & $\begin{array}{c}-/ 185 \\
(-)\end{array}$ & $\begin{array}{c}-/ 148 \\
(-)\end{array}$ & $\begin{array}{c}-/ 118 \\
(-)\end{array}$ & $\begin{array}{c}-/ 46 \\
(-)\end{array}$ & $\begin{array}{c}-/ 20 \\
(-)\end{array}$ & $\begin{array}{c}-/ 37 \\
(-)\end{array}$ & $\begin{array}{c}-/ 47 \\
(-)\end{array}$ & $\begin{array}{c}-/ 43 \\
(-)\end{array}$ & $\begin{array}{c}-/ 24 \\
(-)\end{array}$ & $\begin{array}{l}3 / 1.094 \\
(0,27 \%)\end{array}$ \\
\hline $\begin{array}{l}\text { Sudeste } \\
\text { Paraense }\end{array}$ & $\begin{array}{l}9 / 446 \\
(2,02 \%)\end{array}$ & $\begin{array}{c}15 / 1.132 \\
(1,33 \%)\end{array}$ & $\begin{array}{c}28 / 1.082 \\
(2,59 \%)\end{array}$ & $\begin{array}{l}35 / 700 \\
(5,00 \%)\end{array}$ & $\begin{array}{l}10 / 493 \\
(2,03 \%)\end{array}$ & $\begin{array}{l}7 / 359 \\
(1,95 \%)\end{array}$ & $\begin{array}{l}1 / 158 \\
(0,63 \%)\end{array}$ & $\begin{array}{c}8 / 149 \\
(5,37 \%)\end{array}$ & $\begin{array}{c}-/ 82 \\
(-)\end{array}$ & $\begin{array}{c}-/ 129 \\
(-)\end{array}$ & $\begin{array}{c}113 / 4.730 \\
(2,39 \%)\end{array}$ \\
\hline $\begin{array}{l}\text { Nordeste } \\
\text { Paraense }\end{array}$ & $\begin{array}{c}4 / 272 \\
(1,47 \%)\end{array}$ & $\begin{array}{l}27 / 310 \\
(8,71 \%)\end{array}$ & $\begin{array}{c}6 / 334 \\
(1,80 \%)\end{array}$ & $\begin{array}{c}-/ 187 \\
(-)\end{array}$ & $\begin{array}{l}3 / 159 \\
(1,89 \%)\end{array}$ & $\begin{array}{c}-/ 105 \\
(-)\end{array}$ & $\begin{array}{c}-/ 164 \\
(-)\end{array}$ & $\begin{array}{c}-/ 453 \\
(-)\end{array}$ & $\begin{array}{l}1 / 381 \\
(0,26 \%)\end{array}$ & $\begin{array}{c}-/ 265 \\
(-)\end{array}$ & $\begin{array}{c}41 / 2.630 \\
(1,56 \%)\end{array}$ \\
\hline $\begin{array}{l}\text { Metropolitana } \\
\text { de Belém }\end{array}$ & $\begin{array}{c}-/ 242 \\
(-)\end{array}$ & $\begin{array}{l}1 / 452 \\
(0,22 \%)\end{array}$ & $\begin{array}{l}1 / 544 \\
(0,18 \%)\end{array}$ & $\begin{array}{l}1 / 587 \\
(0,17 \%)\end{array}$ & $\begin{array}{c}-/ 514 \\
(-)\end{array}$ & $\begin{array}{c}-/ 373 \\
(-)\end{array}$ & $\begin{array}{c}-/ 498 \\
(-)\end{array}$ & $\begin{array}{l}1 / 591 \\
(0,17 \%)\end{array}$ & $\begin{array}{l}2 / 340 \\
(0,59 \%)\end{array}$ & $\begin{array}{c}-/ 223 \\
(-)\end{array}$ & $\begin{array}{l}6 / 4.364 \\
(0,14 \%)\end{array}$ \\
\hline $\begin{array}{l}\text { Localização } \\
\text { desconhecida }\end{array}$ & $\begin{array}{l}-/- \\
(-)\end{array}$ & $\begin{array}{l}-/ 2 \\
(-)\end{array}$ & $\begin{array}{l}-16 \\
(-)\end{array}$ & $\begin{array}{l}-/ 1 \\
(-)\end{array}$ & $\begin{array}{l}-/- \\
(-)\end{array}$ & $\begin{array}{l}-/- \\
(-)\end{array}$ & $\begin{array}{l}-/- \\
(-)\end{array}$ & $\begin{array}{l}-/- \\
(-)\end{array}$ & $\begin{array}{l}-/- \\
(-)\end{array}$ & $\begin{array}{l}-/- \\
(-)\end{array}$ & $\begin{array}{l}-19 \\
(-)\end{array}$ \\
\hline Total & $\begin{array}{c}16 / 1.531 \\
(1,05 \%)\end{array}$ & $\begin{array}{c}43 / 2.359 \\
(1,82 \%)\end{array}$ & $\begin{array}{c}43 / 2.324 \\
(1,85 \%)\end{array}$ & $\begin{array}{c}38 / 1.726 \\
(2,20 \%)\end{array}$ & $\begin{array}{c}14 / 1.324 \\
(1,06 \%)\end{array}$ & $\begin{array}{l}7 / 937 \\
(0,75 \%)\end{array}$ & $\begin{array}{c}3 / 931 \\
(0,32 \%)\end{array}$ & $\begin{array}{l}9 / 1.302 \\
(0,69 \%)\end{array}$ & $\begin{array}{c}3 / 878 \\
(0,34 \%)\end{array}$ & $\begin{array}{c}-1675 \\
(-)\end{array}$ & $\begin{array}{c}176 / 13.987 \\
(1,26 \%)\end{array}$ \\
\hline
\end{tabular}

Sinal convencional utilizado: - Dado numérico igual a zero, não resultante de arredondamento.

Durante o período avaliado, foram analisados encéfalos de quatro símios e todos apresentaram resultados negativos para a raiva. Esses resultados diferem dos encontrados na Região Nordeste, que evidenciaram a epidemiologia da raiva em ambiente silvestre. No período de 1990 a 2005, foram relatados 198 casos de raiva em símios, sendo que 13 dos 40 casos de raiva humana relatados no estado do Ceará tiveram a fauna silvestre como fonte de infecção ${ }^{24}$, descrevendo esses animais como reservatórios silvestres do RABV.

Por ser uma doença cíclica, a raiva possui períodos de reaparecimento em torno de sete anos, devido, talvez, a um maior número de morcegos infectados nos picos de grande incidência da doença nos herbívoros, seguido de um declínio para, então, haver um repovoamento e reinfecção das colônias de morcegos ${ }^{20}$. Mesmo com números reduzidos de casos de raiva em quirópteros, é indiscutível a existência da circulação viral entre essa espécie, uma vez que, dos 4.797 quirópteros analisados, 13 (0,27\%) foram positivos para raiva, sendo sete da espécie Desmodus rotundus, quatro da Artibeus planirostris, um da Eptesicus brasiliensis e um da Artibeus obscurus. Quanto à distribuição geográfica dos quirópteros positivos, quatro eram oriundos da Mesorregião Metropolitana de Belém, seis do Nordeste Paraense, dois do Sudeste Paraense e um do Marajó, sendo que, nas três últimas messoregiões, grande parte da economia dos municípios é gerada pela pecuária, ou seja, é comum a presença de grandes rebanhos de gado nessas regiões, proporcionando uma abundância de alimento para morcegos hematófagos ${ }^{25}$.

Chances reais de sucesso no combate à raiva podem ser obtidas quando se alia um programa efetivo de educação sanitária às práticas de vigilância epidemiológica, contemplando orientações aos produtores acerca dos cuidados a serem aplicados quando constatada a presença de morcegos transmissores da doença em suas propriedades, quer seja com a vacinação antirrábica dos animais ou com a notificação de casos da doença às autoridades competentes ${ }^{26}$. Tais atitudes podem ter contribuído para o que foi observado neste levantamento, 0,27\% (13/4.797) de prevalência entre os morcegos examinados. Contudo, não é prudente desprezar os riscos para a saúde pública e a relevância desse resultado.

Em 2004, foram relatados dois surtos de raiva humana no Pará, nos quais os morcegos hematófagos foram os responsáveis pela transmissão. As epidemias ocorreram no município de Portel, localizado na Mesorregião Marajó, onde foram relatados 15 óbitos, dos quais 10 foram confirmados laboratorialmente, e no município de Viseu, localizado no Nordeste Paraense, seis óbitos confirmados laboratorialmente. Em 2005, no município de Augusto Corrêa, também no Nordeste Paraense, ocorreram 15 óbitos, dos quais 10 foram confirmados 
por análises laboratoriais. Nesse mesmo ano, os municípios de Godofredo Viana, Cândido Mendes, Carutapera e Turiaçu, no estado do Maranhão, também relataram surtos de raiva, com a ocorrência de 24 casos em humanos, que estavam fortemente relacionados à proximidade da população com o habitat natural de animais silvestres, nesses casos, os quirópteros. Portanto, além do envio constante de amostras para exame laboratorial, os estudos ecológicos são de extrema importância, a fim de se conhecer mais profundamente o impacto causado por ações humanas, estreitando a relação do homem com esses animais ${ }^{27,28,29}$.

São muitos os problemas relacionados à raiva, sejam eles em animais de produção, domésticos ou silvestres, e talvez mais graves ainda sejam os problemas de saúde pública. A subnotificação dos casos suspeitos é um grande empecilho, visto que não mostra a real situação da raiva na região, o que pode levar a falsas conclusões sobre o controle da doença. A educação sanitária e a conscientização dos profissionais que atuam nessa área e também da sociedade, em geral, continuam sendo ferramentas importantes para o controle efetivo da doença. Apesar da raiva animal, em seu ciclo urbano, estar sendo paulatinamente reduzida ao longo dos anos, a doença ainda continua sendo um problema de saúde pública caracterizado como negligenciado.

\section{CONCLUSÃO}

No período de 2004 a 2013, os dados do Laboratório de Diagnóstico de Raiva da SAARB/IEC demonstraram que o maior número de amostras analisadas e positivas foi da espécie canina. Observou-se a diminuição da prevalência de raiva animal entre todas as espécies abordadas neste trabalho, alertando para os casos de negligência e subnotificação da doença. Foi possível identificar, no período estudado, que a Mesorregião Sudoeste Paraense apresentou o maior percentual de positividade e a espécie com o maior índice positivo foi a equina, seguida da bovina e suína.

Os resultados apresentados neste estudo enfatizam a relevância das campanhas de vacinação de animais domésticos para o controle da raiva urbana, bem como ressalta-se também a importância da imunização anual de animais de produção, a fim de reduzir a incidência e letalidade da doença. Este levantamento é uma ferramenta importante para futuros inquéritos epidemiológicos e contribui para o planejamento de ações preventivas e de controle da raiva, visto que possibilita o panorama da situação epidemiológica da doença no estado do Pará.

\section{AGRADECIMENTOS}

A Mário Nazareno Pinto Ferro, aos coordenadores de Raiva e Zoonoses da Secretaria Estadual de Saúde e da Agência de Defesa Agropecuária do Estado do Pará, bem como às unidades das secretarias municipais de saúde pelo encaminhamento das amostras para diagnóstico. Aos Drs. Pedro Fernando da Costa Vasconcelos e Sueli Guerreiro Rodrigues, que, na qualidade de diretor e chefe de seção, respectivamente, sempre incentivaram a pesquisa e o desenvolvimento científico.

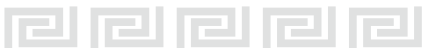

\section{REFERÊNCIAS}

1 Alves LM, Soares RM, Cortez A, Richtzenhain LJ, Ito FN. Pathogenesis of rabies virus by ERA and PV strains administered orally in hamsters (M. auratus). Braz J Vet Res Anim Sci. 2003;40(1):79-84.

2 International Committee on Taxonomy of Viruses. Virus taxonomy: 2016 Release; 2017.

3 Hinrichsen SL, Nova AV, Rengell FS. Raiva. In: Focaccia R, Veronesi R, editores. Tratado de infectologia. 3. ed. São Paulo: Atheneu; 2005. p. 633-48.

4 Takaoka NY, Kotait I, Reichmann MLMAB, Carrieri ML, Panachão MRI, Harmani NMS, et al. Raiva: controle e profilaxia humana. São Paulo: Instituto Pasteur; 2003.

5 Ministério da Saúde (BR). Secretaria de Vigilância em Saúde. Guia de vigilância epidemiológica. 7. ed. Brasília: Ministério da Saúde; 2009. Cad. 13, p. 1-31. (Série A. Normas e manuais técnicos).

6 Mattos CA, Mattos CC, Rupprecht CE. Rhabdoviruses. In: Knipe DM, Howley PM, editors. Fields virology. 4th ed. Philadelphia: Lippincott Williams \& Wilkins; 2001. p. 1245-78.
7 Rupprecht CE, Hanlon CA, Hemachudha T. Rabies re-examined. Lancet InfectDis. 2002 Jun;2(6):327-43.

8 Hampson K, Coudeville L, Lembo T, Sambo M, Kieffer A, Attlan M, et al. Estimating the global burden of endemic canine rabies. PLoS Negl Trop Dis. 2015 Apr;9(4):e0003709.

9 Souza W, coordenador. Doenças negligenciadas. Rio de Janeiro: Academia Brasileira de Ciências; 2010. 56 p. (Ciência e tecnologia para o desenvolvimento nacional. Estudos estratégicos).

10 Ministério da Saúde (BR). Secretaria de Vigilância em Saúde. Manual de diagnóstico laboratorial da raiva. Brasília: Ministério da Saúde; 2008. (Série A. Normas e manuais técnicos).

11 Ministério da Saúde (BR). Secretaria de Vigilância em Saúde. Guia de vigilância epidemiológica. Brasília: Ministério da Saúde; 2014. p. 687-716.

12 Andrade FAG, Gomes MN, Uieda W, Begot AL, Ramos OS, Fernandes MEB. Geographical analysis for detecting high-risk areas for bovine/human rabies transmitted by the common hematophagous bat in the Amazon Region, Brazil. PLoS One. 2016 Jul;11(7):e0157332. 
13 Costa LJC, Fernandes MEB. Rabies: knowledge and practices regarding rabies in rural communities of the Brazilian Amazon basin. PLoS Negl Trop Dis. 2016 Feb; 10(2):e0004474.

14 Dean DJ, Abelseth MK, Atanasiu P. The fluorescent antibody test. In: Meslin FX, Kaplan MM, Koprowski $\mathrm{H}$, editors. Laboratory techniques in rabies. 4th ed. Geneva: World Health Organization; 1996. Ch. 7, p. 88-95.

15 Koprowski $H$. The mouse inoculation test. In: Meslin FX, Kaplan MM, Koprowski H, editors. Laboratory techniques in rabies. 4th ed. Geneva: World Health Organization; 1996. Ch. 6, p. 80-7.

16 Webster LT, Dawson Jr. JR. Early diagnosis of rabies by mouse inoculation. Measurement of humoral immunity to rabies by mouse protection test. Exp Biol Med (Maywood). 1935 Jan;32(4):570-3.

17 Meslin FX, Kaplan MM. An overview of laboratory techniques in the diagnosis and prevention of rabies and in rabies research. In: Meslin FX, Kaplan MM, Koprowski H, editors. Laboratory techniques in rabies. 4th ed. Geneva: World Health Organization; 1996. Ch. 2, p. 9-27.

18 Ito M, Arai YT, Itou T, Sakai T, Ito FH, Takasaki T, et al. Genetic characterization and geographic distribution of rabies virus isolates in Brazil: identification of two reservoirs, dogs and vampire bats. Virology. 2001 Jun;284(2):214-22.

19 Caldas EP. Situação da Raiva no Brasil. [Palestra apresentada no] $8^{\circ}$ Seminário do Dia Mundial contra a Raiva [Internet]. 2015 set 28-30 [citado 2017 out 17]. Disponível em: http://saude.sp.gov. $\mathrm{br} /$ resources/instituto-pasteur/pdf/wrd2015/situaca odaraivanobrasil-eduardopachecodecaldas.pdf.

20 Casseb LMN. Estudo epidemiológico da raiva, caracterização antigênica e genética de cepas do vírus da raiva isoladas na Amazônia brasileira [dissertação]. Belém (PA): Universidade Federal do Pará, Núcleo de Medicina Tropical; 2009. 157 p.

21 Vaz JAMC. Raiva em herbívoros - situação no Brasil. [Palestra apresentada no] $6^{\circ}$ Seminário Dia Mundial contra a Raiva [Internet]. 2013 out 16 [citado 2015 abr 23]. Disponível em: http://www.saude. sp.gov.br/resources/instituto-pasteur/pdf/wrd2013/ raivaemherbivorossituacaonobrasiljuliana.pdf.
22 Ministério da Saúde (BR). Serviço de Vigilância Sanitária. Situação epidemiológica das zoonoses de interesse para à saúde pública. Bol Eletr Epidemiol. 2009 jun;9(1):1-17.

23 Menezes FL, Silva JA, Moreira EC, Meneses JNC, Magalhães DF, Barbosa AD, et al. Distribuição espaço-temporal da raiva bovina em Minas Gerais, 1998 a 2006. Arq Bras Med Vet Zootec. 2008;60(3):566-73.

24 Aguiar TDF, Costa EC, Rolim BN, Romijn PC, Morais NB, Teixeira MFS. Risco de transmissão do vírus da raiva oriundo de sagui (Callithrix jacchus), domiciliado e semidomiciliado, para o homem na região metropolitana de Fortaleza, Estado do Ceará. Rev Soc Bras Med Trop. 2011 mai-jun;44(3):356-63.

25 Instituto Brasileiro de Geografia e Estatística. Produção da pecuária municipal [Internet]. Rio de Janeiro: IBGE; 2016 [citado 2019 abr 23]. Disponível em: https://www.ibge.gov.br/estatisticas/ economicas/agricultura-e-pecuaria/9107-producao -da-pecuaria-municipal.html $2=\& t=$ downloads.

26 Schneider MC, Almeida GA, Souza LM, Morares NB, Diaz RC. Controle da raiva no Brasil de 1980 a 1990. Rev Saude Publica. 1996 abr;30(2): 196-203.

27 Barbosa TFS. Caracterização molecular de cepas do Vírus da raiva (Lyssavirus; Rhabdoviridae) isoladas no estado do Pará [dissertação]. Belém: Universidade Federal do Pará, Centro de Ciências Biológicas; 2007. 110 p.

28 Travassos da Rosa ES, Kotait I, Barbosa TFS, Carrieri $M L$, Brandão PE, Pinheiro AS, et al. Bat-transmitted human rabies outbreaks, Brazilian Amazon. Emerg Infect Dis. 2006 Aug;12(8):1 197-202.

29 Casseb LMN, Barbosa TFS, Pereira AS, Vieira CA, Medeiros DBA, Vasconcelos PFC, et al. Prevalência de raiva animal em amostras procedentes da Região Norte do Brasil, diagnosticadas no Instituto Evandro Chagas no período de 2000 a 2004. Rev Cienc Agrar. 2006 jul-dez;46:261-74. 